\section{Advocacy: Why and How} Society, you are probably aware that MRS dedicates a substantial amount of volunteer effort to communicating with the U.S. federal government in support of sound science policy.* To get a sense of what MRS is doing in science advocacy, just click on the drop-down menu items under the "Advocacy" menu bar item on the MRS Web site at www.mrs.org. In this letter, I want to tell you why MRS is engaged in these efforts and how you can be involved.

Federal funding for basic research is important. It is widely accepted that economic growth and dramatically increased quality of life result from knowledgeintensive technology developments. ${ }^{\dagger}$ In addition to direct benefits (e.g., life- or labor-saving devices), a substantial fraction of worldwide economic growth can be attributed to technology development. Technology development is, in turn, fueled by basic research, which, while motivated primarily by curiosity, builds intellectual capital and lays the groundwork for future technologies. $\ddagger$ However, basic research generally has low short-term returns. Due to the long time horizon and uncertainty for return on investment, only governments can provide the sustained investment in basic research necessary to maintain technology development in an open global economy.

The United States has the world's largest economy and makes the largest investments in science and technology in absolute terms; thus, it makes sense for MRS to work to influence the U.S. government. As shown in Figure 1, the U.S. federal budget consists of mandatory parts (primarily Medicaid, Medicare, and Social Security), which must be funded unless the laws that created them are changed, and discretionary parts that are decided every year. Funding for research is part of the discretionary budget.

It is important to realize that there is no such thing as "stable funding" for science

*You can also find a summary of recent initiatives written by 2008 MRS President, Cynthia A. Volkert, in the December 2008 issue of MRS Bulletin (p. 1132).

${ }^{+}$Science and Engineering Indicators 2008 (National Science Board, National Science Foundation, 2008; www.nsf.gov/statistics/ seind08) (accessed February 2009).

$\ddagger$ Rising Above the Gathering Storm: Energizing and Employing America for a Brighter Economic Future (National Academies Press, 2007; http://books.nap.edu/catalog. php?record_id=11463) (accessed February 2009).
As a member of the Materials Research

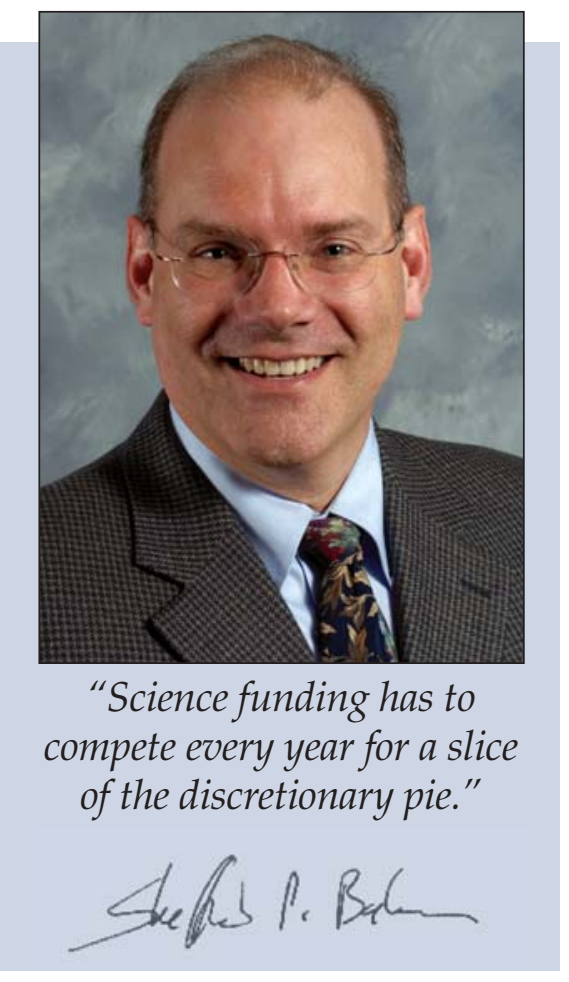

in the United States. Science funding has to compete every year for a slice of the discretotal federal budget. In addition to science tionary pie, which is only about $1 / 3$ of the funding, this portion of the federal budget includes a huge range of activities, including Defense, Health and Human Services, Education, and many others. Members of Congress, as well as the citizens of the United States, are generally very supportive of science, but it is always necessary to justify and prioritize expenditures on the discretionary side. This is especially true in these challenging economic times.

Helping the legislative and executive branches to justify and prioritize science funding is the main reason for MRS advocacy efforts. In the past, the "cold war" and the "space race" provided simple focal points for physical sciences advocacy efforts. In the future, pressing issues such as energy may also provide such focal points. While such issues can help to spur action, enthusiasm for them continually waxes and wanes. Thus it is critically important to continually inform lawmakers of the value of science and of the policies and procedures that best support it.

Effective advocacy requires a clear message repeated frequently by many different voices. Accordingly, MRS "aims high" with advocacy messages. We champion enhanced funding for physical sciences research in general and programs that support that goal, rather than specific issues or programs that might primarily affect one institution, region, or sector. As

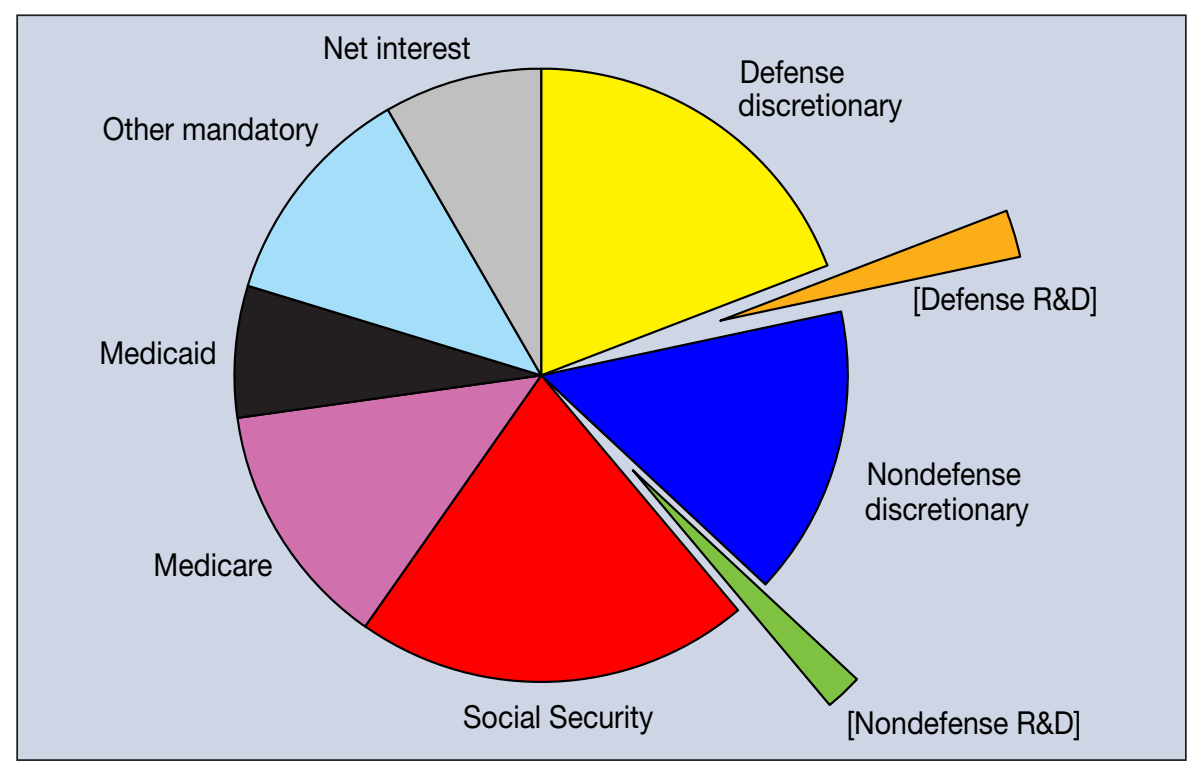

Figure 1. U.S. 2009 budget allocations as proposed in 2008. Note: Projected Unified deficit is $\$ 407$ billion. Figures exclude most Iraq and Afghanistan military costs. Source: AAAS, based on Budget of the United States Government FY 2009. (February 2008).

\$AAAS Report XXXIII: Research and Development FY 2009 (American Association for the Advancement of Science, 2008; www.aaas.org/spp/rd/rd09main.htm) (accessed February 2009). 
is always true for Congress, the number of voices matters. The more constituents who contact congressional offices with the same clear message, the more likely that message will be received and acted on. Even non-citizen U.S. residents, U.S. citizens living outside the United States, and international voices are heard (in different ways) by congressional delegations.

For this reason, it is very important that MRS members participate to the largest extent possible in MRS advocacy activities. Here are four things that you can do that have real impact on the legislative process:

- Stay informed on the issues. You can always find out what MRS is working on by clicking on the "News Alerts" or "Issues" buttons on the Advocacy pulldown menu on the MRS home page at www.mrs.org.

- Communicate with your senators and representative about critical issues. MRS makes this easy through the "Materials Voice" program. To find pre-formulated letters that you can modify and send, just click on the "Materials Voice" button on the "Advocacy" pull-down menu. Alternatively, access Materials Voice directly at Web site www.mrs.org/ materialsvoice. This will take only a few minutes of your time.

- Visit your senators and representative. You can visit them in their offices in your home state, or you can participate in the "Congressional Visits Days" organized and sponsored by MRS. These well-orchestrated events allow MRS members to deliver the MRS advocacy message personally to Congressional offices. For more information, contact Sandra DeVincent Wolf, publicaffairs@mrs.org, at MRS headquarters.

- Use your position to help members of your community express their support for science and science funding. MRS advocacy resources (e.g., Web site, Materials Voice) are freely available. Use those resources to inform friends, neighbors, and community groups of the critical issues facing science and science funding and encourage them to communicate their support for science to Congress and the administration.

If you are one of the $40 \%$ or so of MRS members who are living outside the
United States, you may well be asking yourself "what does this have to do with me?" The answer is, "plenty." Science and discovery are apolitical and do not recognize borders. Investments in science anywhere benefit people everywhere. MRS is working to form partnerships with sister societies around the world to find ways to help governments everywhere to support and benefit from scientific advancements. Your input will be very important to this process.

In summary, MRS participates in advocacy in order to assist governments in developing sound science policy (including funding) to the benefit of people everywhere. You can participate by joining any of the activities in the bulleted list or on the MRS Web site. If you want to do more, please contact the MRS Government Affairs Committee (for contact information, press the "Government Affairs Committee" button in the "Advocacy" pull-down menu on the MRS Web site at www.mrs.org). Your active participation will make a difference.

SHEFFORD P. BAKER 2009 MRS President
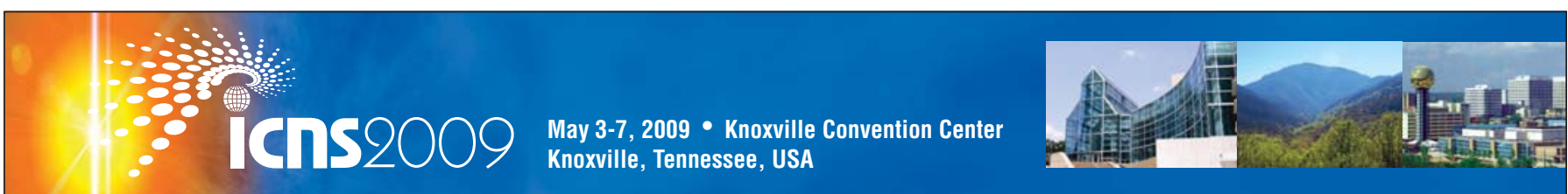

\section{International Conference on Neutron Scatering}

Official Sponsor-Neutron Scattering Society of America (NSSA)

Conference Host-Oak Ridge National Laboratory

Mark your calendar now and plan to attend the 2009 International Conference on Neutron Scattering (ICNS2009) in Knoxville, Tennessee. This is the 9th ICNS in the series since the conferences began with ICNS ' 82 in Hakone, Japan, and follows ICNS 2005 in Sydney, Australia.

Whether you are already a neutron user, or would simply like to learn how neutrons can help solve your problems in the materials and biological sciences, this is the essential venue to hear about the high-quality and breadth of current neutron-related research worldwide.
ICNS2009 will provide an opportunity to:

- share new results enabled by neutron scattering experiments in scientific and engineering fields including:

Soft Condensed Matter

Biological Sciences

Condensed Matter Physics

Chemistry/Earth Sciences

Engineered and Applied Materials

Neutron Physics

Instrument Concepts/Techniques/Devices

Sample Environment

Software

Facilities/Source Development
- present ideas on new and novel techniques in the field of neutron scattering

- promote collaborations and interdisciplinary partnerships

- feature updates on facility development and expanding capabilities for advanced neutron sources

- discuss how neutron scattering might expand its role in the study of new and emerging scientific topics

NSSA is partnering with the Materials Research Society for the conference organization. For the most up-to-date information on ICNS2009 visit www.mrs.org/icns2009 